\title{
Heterogeneous distribution of ${ }^{60} \mathrm{Fe}$ in the early solar nebula: Achondrite evidence
}

\author{
Naoji Sugiura ${ }^{1}$, Akiko Miyazaki ${ }^{1}$, and Qing-zhu Yin ${ }^{2}$ \\ ${ }^{1}$ Department of Earth and Planetary Science, University of Tokyo, Tokyo, Japan \\ ${ }^{2}$ Department of Geology, University of California at Davis, Davis, California 95616, U.S.A.
}

(Received December 2, 2005; Revised April 15, 2006; Accepted April 20, 2006; Online published September 16, 2006)

\begin{abstract}
${ }^{60} \mathrm{Fe}-{ }^{60} \mathrm{Ni}$ systematics in quenched angrites and two old eucrites were investigated by secondary ion mass spectrometry. The ${ }^{60} \mathrm{Ni} /{ }^{62} \mathrm{Ni}$ isotopic compositions were normal within $2 \sigma$ errors. The inferred initial ${ }^{60} \mathrm{Fe} /{ }^{56} \mathrm{Fe}$ ratios for quenched angrites was $(6 \pm 9) \times 10^{-9}$, and similar upper limit values were also obtained from eucrites. Using the age difference of approximately $5 \mathrm{Ma}$ between the quenched angrites and $\mathrm{Ca}-\mathrm{Al}$-rich inclusions, the initial ${ }^{60} \mathrm{Fe} /{ }^{56} \mathrm{Fe}$ ratio at the start of the solar system was calculated to be approximately $(6 \pm 9) \times 10^{-8}$. This initial ratio is significantly smaller than previously published values obtained from chondritic materials, suggesting the heterogeneous distribution of ${ }^{60} \mathrm{Fe}$ in the solar nebula.
\end{abstract}

Key words: Solar nebula, ${ }^{60} \mathrm{Fe}$, angrite, eucrite, SIMS, age.

\section{Introduction}

The presence of now-extinct nuclides, such as ${ }^{26} \mathrm{Al}$ (halflife: $0.7 \mathrm{Ma}$ ), in the early solar system is well established (MacPherson et al., 1995). However, their origin (produced by supernova or by cosmic ray irradiation) and distribution in the solar system are a matter of contentious debate. (Goswami et al., 2005).

${ }^{60} \mathrm{Fe}$, which decays to ${ }^{60} \mathrm{Ni}$ with a half-life of $1.5 \mathrm{Ma}$, is mainly produced by supernovae under a neutron-rich environment since high neutron fluence is needed to produce ${ }^{60} \mathrm{Fe}$ from ${ }^{59} \mathrm{Fe}$ before it decays to ${ }^{59} \mathrm{Co}$. Cosmic ray irradiation is a potentially important mechanism for producing some of the now-extinct nuclides, such as ${ }^{10} \mathrm{Be}$ (Goswami et al., 2005). ${ }^{60} \mathrm{Fe}$, however, is not produced efficiently by the cosmic ray irradiation and, as a result, the presence of ${ }^{60} \mathrm{Fe}$ in meteorites provides strong evidence for supernova product in the solar nebula. Once the abundance of ${ }^{60} \mathrm{Fe}$ is established, then abundances of the other extinct nuclides (such as ${ }^{26} \mathrm{Al}$ ) co-produced in supernova can be estimated (Wasserburg et al., 1998). The radioactive decay of ${ }^{60} \mathrm{Fe}$ is also a potentially important heat source (Shukolyukov and Lugmair, 1993a) for the early differentiation of asteroid bodies as ${ }^{60} \mathrm{Fe}$ supplements and extends the heat source of ${ }^{26} \mathrm{Al}$ due to its longer half-life than ${ }^{26} \mathrm{Al}$.

There are many reports on the presence of ${ }^{60} \mathrm{Fe}$ in meteorites. An up-to-date review of this subject was provided by Kita et al. (2005). In essence, the first hint of ${ }^{60} \mathrm{Fe}$ in the solar system was obtained from nickel isotopic compositions of Ca-Al-rich inclusions (CAIs) (Birck and Lugmair, 1988). The isotopic anomalies on ${ }^{62} \mathrm{Ni}$ and ${ }^{64} \mathrm{Ni}$ observed in these CAIs, however, leave the possibility that the ${ }^{60} \mathrm{Ni}$ anomaly is of nucleosynthetic origin rather than from the decay of

Copyright (c) The Society of Geomagnetism and Earth, Planetary and Space Sciences (SGEPSS); The Seismological Society of Japan; The Volcanological Society of Japan; The Geodetic Society of Japan; The Japanese Society for Planetary Sciences; TERRAPUB.
${ }^{60} \mathrm{Fe}$. More reliable evidence for the presence of ${ }^{60} \mathrm{Fe}$ in the solar nebula was obtained by nickel isotope analyses of eucrites (Shukolyukov and Lugmair, 1993a, b). Unfortunately, it is not easy to obtain the initial ${ }^{60} \mathrm{Fe} /{ }^{56} \mathrm{Fe}$ ratio at the start of the solar system from these eucrite data because some of these eucrites show signs of disturbance due to shock heating; as such, the closure time of the Fe-Ni system is poorly constrained. The latest report by these authors suggested that the initial ${ }^{60} \mathrm{Fe} /{ }^{56} \mathrm{Fe}$ for the solar system was $2 \sim 19 \times 10^{-8}$ (Shukolyukov and Lugmair, 1996).

There are several studies of ${ }^{60} \mathrm{Fe}-{ }^{60} \mathrm{Ni}$ systematics on sulfides in primitive meteorites (e.g. Tachibana and Huss, 2003; Mostefaoui et al., 2004b, 2005), although sulfides can be disturbed at rather low temperatures. Therefore, it is not known whether sulfides can serve as a faithful recorder of ${ }^{60} \mathrm{Fe} /{ }^{56} \mathrm{Fe}$ ratios in the solar nebula (Kita et al., 2005).

Kita et al. (2005) suggests that Fe-rich silicates in chondrules potentially provide the most reliable record of ${ }^{60} \mathrm{Fe}$ in the solar system because silicates are stable (have high closure temperatures) and because the range of chondrule ages in primitive chondrites is fairly well restricted. A few studies have investigated this approach (Choi et al., 1999; Kita et al., 2000; Tachibana et al., 2006). Kita et al. (2000) obtained an upper limit of ${ }^{60} \mathrm{Fe} /{ }^{56} \mathrm{Fe}=1.4 \times 10^{-7}$ for Semarkona chondrules, while Choi et al. (1999) obtained ${ }^{60} \mathrm{Fe} /{ }^{56} \mathrm{Fe}=(4.8 \pm 11.8) \times 10^{-7}$ for Bishunpur and Chainpur chondrules. Tachibana et al. (2006) reported that the initial ratios of ${ }^{60} \mathrm{Fe} /{ }^{56} \mathrm{Fe}$ ranged from $2 \times 10^{-7}$ to $4 \times 10^{-7}$ for Semarkona and Bishunpur chondrules. The range reported by Tachibana et al. (2006) is in apparent conflict with the upper limit reported by Kita et al. (2000). In summary, the abundance of ${ }^{60} \mathrm{Fe}$ in the early solar system is not well constrained and, consequently, further work is needed due to the importance of this nuclide in elucidating the history of the early solar system.

To estimate the abundance of ${ }^{60} \mathrm{Fe}$ in the solar system 
precisely and accurately from nickel isotopic analyses of meteorites, there are several requirements that have to be fulfilled. First, the meteorite has to be old and the age must be well constrained. Second, it has to contain minerals with high $\mathrm{Fe} / \mathrm{Ni}$ ratios. Third, $\mathrm{Ni}$ isotopic ratios have to be determined precisely. Fourth, $\mathrm{Fe} / \mathrm{Ni}$ ratios have to be determined accurately. Fifth, the Fe-Ni system should not have been disturbed to significant extent. We report here $\mathrm{Ni}$ isotopic compositions in Fe-rich silicates in some achondrites. The inferred ${ }^{60} \mathrm{Fe} /{ }^{56} \mathrm{Fe}$ ratios for the solar system determined from this study provide one of the most stringent constraints on ${ }^{60} \mathrm{Fe}$ abundance. A preliminary report of the work reported here has been published in abstract form by Sugiura and Yin (2005).

\section{Experimental}

\subsection{Meteorite samples and the chronology}

Achondrites are produced from the mantle of parentbodies that are depleted in $\mathrm{Ni}$ due to $\mathrm{Ni}$ being preferentially extracted to the core relative to Fe. For this reason, angrites, eucrites and ureilites are suitable for the search of ${ }^{60} \mathrm{Fe}$. There is a group of angrites called "quenched angrites" (Mikouchi et al., 2001) because their texture suggests a rapid cooling from high temperatures. Four of these angrites (D'Orbigny, Sahara 99555, Northwest Africa 1670 and Asuka 881371) were included in this study. These angrites have been studied with various chronological systems. Mn-Cr chronological data of quenched angrites have been reported by Nyquist et al. (2003a), Glavin et al. (2004) and Sugiura et al. (2005). These $\mathrm{Mn}-\mathrm{Cr}$ studies revealed that quenched angrites have identical ages that are 4 5 Ma older than LEW 86010 and Angra dos Reis. Using the $\mathrm{Mn}-\mathrm{Cr}$ age and the $\mathrm{Pb}-\mathrm{Pb}$ age ( $\sim 558 \mathrm{Ma})$ of LEW 86010 (Lugmair and Shukolyukov, 1998), researchers have determined the absolute ages of these angrites to be $4562 \sim 4563$ Ma. Al-Mg data of D'Orbigny and Sahara 99555 were reported by Spivak-Birndorf et al. (2005a, b). Using the CAI age of $4567.4 \pm 1.1 \mathrm{Ma}$ (Amelin et al., 2002) and these $\mathrm{Al}-\mathrm{Mg}$ data, the absolute age of these angrites were calculated to be $4562.5 \sim 4562.7 \mathrm{Ma}$. The recently obtained $\mathrm{Pb}$ $\mathrm{Pb}$ age of D'Orbigny (4563.9 $\pm 0.6 \mathrm{Ma})$ and Asuka 881371 (4562.4 $\pm 1.6 \mathrm{Ma})$ (Zartman et al., 2006) appears to be consistent with the ages based on Al-Mg and Mn-Cr systematics. A recent report by Baker et al. (2005), however, suggests that the absolute age for quenched angrites is $\sim 4566$ $\mathrm{Ma}$; this estimation was based on new measurements by $\mathrm{Pb}-\mathrm{Pb}$ dating and is not consistent with earlier reports. At present the exact absolute age of quenched angrites is still under debate, but they are undoubtedly very old. We took the absolute age of quenched angrites to be $\sim 4563$ Ma because this gives an upper limit to the initial ${ }^{60} \mathrm{Fe} /{ }^{56} \mathrm{Fe}$ ratio of the solar system. (The age of the solar system is assumed to be the CAI age of $\sim 4568 \mathrm{Ma}$ ). If the angrites are older than $4563 \mathrm{Ma}$, then the initial ${ }^{60} \mathrm{Fe} /{ }^{56} \mathrm{Fe}$ ratio of the solar system becomes even lower. We also examined Angra dos Reis, the type meteorite of angrites, but the data are not included in the present study because the minerals found in Angra dos Reis do not have $\mathrm{Fe} / \mathrm{Ni}$ ratios high enough for dating purposes.

Two eucrites (Asuka 881394 and Stannern) were in- cluded in this study. Asuka 881394 is the oldest eucrite; based on $\mathrm{Mn}-\mathrm{Cr}, \mathrm{Al}-\mathrm{Mg}$ and $\mathrm{Pb}-\mathrm{Pb}$ systematics (Nyquist et al., 2003b; Wadhwa et al., 2005), it is about 4 Ma younger than CAIs and has an absolute age of approximately 4564 Ma. $\mathrm{Pb}-\mathrm{Pb}$ data on Stannern (Tera et al., 1997) suggest that it has been disturbed late in its history, while, in contrast, Hf-W systematics suggests that its Hf-W age is one of the oldest (4564 Ma) among eucrites (Kleine et al., 2005). We have accepted the Hf-W age for calculating the ${ }^{60} \mathrm{Fe} /{ }^{56} \mathrm{Fe}$ initial ratio. The robustness of the $\mathrm{Fe}-\mathrm{Ni}$ system relative to that of the Hf-W or Pb-Pb systems is not well known, thus, the calculated ${ }^{60} \mathrm{Fe} /{ }^{56} \mathrm{Fe}$ initial ratio using the age of 4564 Ma for Stannern must be treated with caution.

\subsection{Target minerals}

In the case of quenched angrites, $\mathrm{Fe} / \mathrm{Ni}$ ratios are high in $\mathrm{Fe}$-rich olivine, although a number of $\mathrm{Fe}$-poor olivines with low $\mathrm{Fe} / \mathrm{Ni}$ ratios also exist, many of which are xenocrysts. By definition, xenocrysts do not share a common origin with the rest of the meteorite; consequently, in the strictest sense they should not be included in isochron. However, since these xenocrysts are Fe-poor, the Ni isotopic compositions are expected to be a reasonable proxy of the initial nickel isotopic composition of achondrites and thus they are useful for the precise determination of the y-intercepts of isochrons. In the case of eucrites, Fe-rich pyroxenes were measured, because olivine grains were not present. In most cases, pyroxene grains contain narrow lamellae of Ca-rich pyroxene which exsolved from Ca-poor pyroxene. Secondary ion mass spectrometry (SIMS) measurements were made in an area approximately $30 \mu \mathrm{m}$ in diameter which includes both $\mathrm{Ca}$-poor and $\mathrm{Ca}$-rich pyroxenes. The volume fraction of Ca-poor pyroxene in SIMS spots is approximately 90\%. Ca-poor pyroxenes contain much higher concentrations of $\mathrm{Ni}$ and $\mathrm{Fe}$ compared to $\mathrm{Ca}$-rich pyroxenes. Lehmann (2003) carried out a SIMS study on the sensitivity of $\mathrm{Fe}$ in pyroxene-composition materials and found that the Fe sensitivity in Ca-poor pyroxene is approximately $30 \%$ higher than that in Ca-rich pyroxene. Based on these three observations, the Fe-Ni systematics measured by SIMS is considered to be entirely determined by $\mathrm{Ca}$ poor pyroxene. The average compositions of pyroxenes over an area approximately $30 \mu \mathrm{m}$ in diameter are rather constant, and there was no mineral present with $\mathrm{Fe} / \mathrm{Ni}$ ratios low enough to be suitable for the precise determination of the y-intercepts of isochrons. Therefore, isochrons were force-fit to terrestrial olivine composition at the origin. This is allowable because measurement errors were much larger than the possible deviations of non-radiogenic $\mathrm{Ni}$ isotopic compositions in these materials.

\subsection{SIMS measurement}

Polished sections were prepared and searched for spots suitable for SIMS analyses with scanning electron microscopy-energy dispersion X-ray spectrometry (SEMEDS) operated at $20 \mathrm{keV}$. An area larger than $30 \mu \mathrm{m}$ in diameter is needed for the precise determination of nickel isotopic compositions. Such areas are ubiquitous in the achondrite samples, with the exception of NWA 1670. This angrite was quenched so rapidly that the average width of the lath-shaped Fe-rich olivine is less than $30 \mu \mathrm{m}$. Nevertheless, more than ten areas large enough for SIMS analysis 


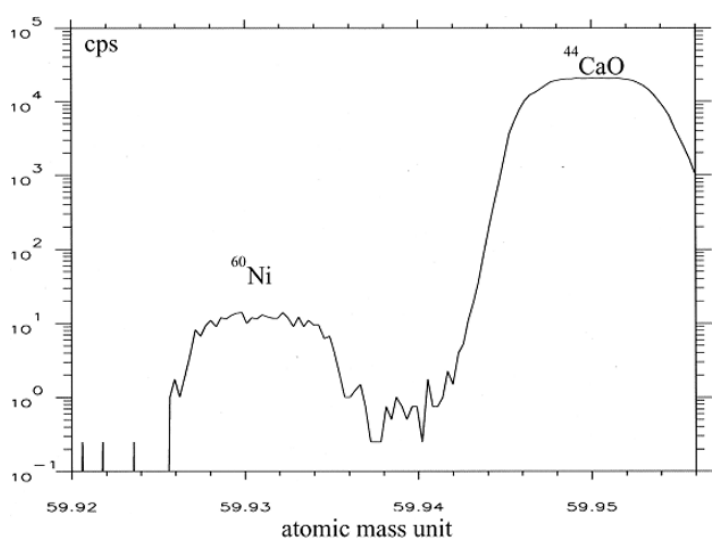

Fig. 1. A mass spectrum around a peak of ${ }^{60} \mathrm{Ni}$ obtained from an olivine grain in Sahara 99555. In this example, the tail of ${ }^{44} \mathrm{CaO}$ at the center of the ${ }^{60} \mathrm{Ni}$ peak is about $1 \%$ of the ${ }^{60} \mathrm{Ni}$ signal.

were found in a polished section of approximately $1 \mathrm{~cm}^{2}$.

An $\mathrm{O}^{-}$primary beam approximately $30 \mu \mathrm{m}$ in diameter was used for sputtering. Secondary ions of ${ }^{57} \mathrm{Fe},{ }^{60} \mathrm{Ni}$ and ${ }^{62} \mathrm{Ni}$ were measured (measurement \#1) at a mass resolving power of approximately 4500 for approximately 30 min. In cases where the ${ }^{57} \mathrm{Fe}$ signal was significantly higher than $10^{5} \mathrm{cps}$, the measurement was made with a Faraday cup; otherwise, measurements were made with an electron multiplier. There were large adjacent peaks of oxide ions adjacent to the $\mathrm{Ni}$ peaks $\left({ }^{44} \mathrm{CaO}\right.$ next to ${ }^{60} \mathrm{Ni}$ and ${ }^{46} \mathrm{TiO}$ next to ${ }^{62} \mathrm{Ni}$ ). A mass spectrum around ${ }^{60} \mathrm{Ni}$ is shown in Fig. 1 in which it can be seen that the tails of these oxide peaks at the positions of the nickel peaks are not negligible, as suggested by Kita et al. (1998). The peak and tail of ${ }^{57} \mathrm{Fe}$ and the peaks of ${ }^{44} \mathrm{CaO}$ and ${ }^{46} \mathrm{TiO}$ were measured (measurement \#2) under the same condition as that of measurement \#1. Measurement \#2 was made for $10 \mathrm{~min}$ only. Tail Corrections were made by ${ }^{44} \mathrm{CaO} \times\left({ }^{57} \mathrm{Fe}\right.$ tail $/{ }^{57} \mathrm{Fe}$ peak) at ${ }^{60} \mathrm{Ni}$ and ${ }^{46} \mathrm{TiO} \times\left({ }^{57} \mathrm{Fe}\right.$ tail $/{ }^{57} \mathrm{Fe}$ peak $)$ at ${ }^{62} \mathrm{Ni}$, respectively. The mass difference between ${ }^{60} \mathrm{Ni}$ and ${ }^{44} \mathrm{CaO}$ is $0.0196 \mathrm{amu}$ (atomic mass unit) and that between ${ }^{62} \mathrm{Ni}$ and ${ }^{46} \mathrm{TiO}$ is $0.0192 \mathrm{amu}$. The tail of the ${ }^{57} \mathrm{Fe}$ peak was measured at 0.0194 amu from the ${ }^{57} \mathrm{Fe}$ peak, and the tailto-peak ratio was used for the corrections of both ${ }^{60} \mathrm{Ni}$ and ${ }^{62} \mathrm{Ni}$. This correction is adequate since the tail is quite flat at a 0.0194 amu distance from the peak. Corrections of the tails were less than $30 \%$ of the measured ${ }^{60} \mathrm{Ni} /{ }^{62} \mathrm{Ni}$ ratios. Errors in the tail correction were estimated to be approximately $20 \%(1 \sigma)$ and propagated to the reported errors. At the mass resolution of approximately 4500 , the ${ }^{56} \mathrm{FeH}$ peak is only partially resolved from the ${ }^{57} \mathrm{Fe}$ peak. However, the hydride peak is always much less than $1 \%$ of the ${ }^{57} \mathrm{Fe}$ peak and is, therefore, practically negligible.

In many SIMS studies in search of ${ }^{60} \mathrm{Ni}$ excesses (e.g. Kita et al., 1998), ${ }^{61} \mathrm{Ni}$ was monitored and used for correcting the variation in the instrumental mass fractionation. However, the isotopic abundance of ${ }^{61} \mathrm{Ni}$ is only one third that of ${ }^{62} \mathrm{Ni}$. This means that if ${ }^{61} \mathrm{Ni}$ is monitored, at least threefold more time is needed to make a measurement as precise as that without ${ }^{61} \mathrm{Ni}$ monitoring. Under our experimental conditions, $1 \sigma$ error of ${ }^{60} \mathrm{Ni} /{ }^{62} \mathrm{Ni}$ for a Fe-rich olivine in angrites is $\leq 23 \%$ o for a 30 -min measurement without ${ }^{61} \mathrm{Ni}$ monitoring. Under similar experimental conditions, repeated measurements of ${ }^{60} \mathrm{Ni} /{ }^{62} \mathrm{Ni}$ of San Carlos olivine over several months gave a $1 \sigma$ deviation of $1.7 \%$. Therefore, it is not good experimental practice to spend a significant amount of time monitoring for the deviation of instrumental mass fractionation. We decided not to monitor ${ }^{61} \mathrm{Ni}$ and instead assumed an uncertainty of $1.7 \%$ or instrumental mass fractionation and subsequently propagated to reported errors. A similar strategy of not monitoring ${ }^{61} \mathrm{Ni}$ was used by Mostefaoui et al. (2004b, 2005) in detecting ${ }^{60} \mathrm{Ni}$ excesses in sulfides.

A relative sensitivity factor is defined by $\left(\mathrm{Ni}^{+} / \mathrm{Fe}^{+}\right) /$ $[\mathrm{Ni} / \mathrm{Fe}]$ where $[\mathrm{Ni} / \mathrm{Fe}]$ represents an atomic abundance ratio. This factor is needed for converting the ionic ratios measured by SIMS to atomic ratios. Fe-rich olivine in an R chondrite (Northwest Africa 99531) was used for the calibration. Its composition was determined with an electron microprobe to be approximately $32 \mathrm{wt} \% \mathrm{FeO}$ and approximately $0.2 \mathrm{wt} . \% \mathrm{NiO}$. The relative sensitivity was estimated to be approximately $0.99 \pm 0.04(1 \sigma)$. This is significantly larger than the sensitivity factor $(\sim 0.74)$ reported by Kita et al. (1998) for olivine with a similar Fe-rich composition. We note that the difference in the sensitivity factor could be due to differences in the primary ion species, i.e. $\mathrm{O}^{-}$in this study versus $\mathrm{O}_{2}^{-}$in that of Kita et al. (1998). At Fepoor compositions ( $\mathrm{Fa \#}<30$, where $\mathrm{Fa \#}$ is fayalite mole $\%$ ), the relative sensitivity increases with the Fa\# (Kita et al., 1998). At higher Fa\# compositions, however, the $\mathrm{Fe} / \mathrm{Ni}$ relative sensitivity in olivine tends to level off at Fa\# 35 (Reed et al., 1979). Steele et al. (1981) also showed that the relative sensitivities of many elements including $\mathrm{Fe}$ do not depend strongly on olivine compositions at Fa\#>35. Therefore, our calibration at $\mathrm{Fa \#} 36(\sim 32 \mathrm{wt} \% \mathrm{FeO})$ is more than adequate for olivines in this study which typically contain approximately $50 \mathrm{wt} . \% \mathrm{FeO}$. We have not determined a relative sensitivity for pyroxene. Kita et al. (1998) suggested that the relative sensitivity for pyroxene is not much different from that for olivine. Therefore, we adopted the same relative sensitivity $(0.99)$ for pyroxene and assumed an uncertainty of approximately $10 \%(1 \sigma)$.

\section{Results}

The $\mathrm{Ni}$ isotopic ratios and ${ }^{57} \mathrm{Fe} /{ }^{62} \mathrm{Ni}$ ratios for angrites and eucrites are shown in Fig. 2. The attached error bars are only $1 \sigma$. All of the Ni isotopic compositions are normal within $2 \sigma$ errors. Since the four quenched angrites have identical $\mathrm{Mn}-\mathrm{Cr}$ ages, the data for these four angrites are combined and shown in Fig. 3. The inferred initial ${ }^{60} \mathrm{Fe} /{ }^{56} \mathrm{Fe}$ ratios are summarized in Table 1.

Table 1 also contains the calculated initial ratios at the beginning of solar system formation. The $\mathrm{Fe} / \mathrm{Ni}$ atomic ratios for angrite olivine are as high as $6 \times 10^{5} .{ }^{57} \mathrm{Fe}$ is $2.12 \%$ of the total $\mathrm{Fe}$ and ${ }^{62} \mathrm{Ni}$ is $3.63 \%$ of the total $\mathrm{Ni}$. Thus, a Fe/Ni ratio is obtained by ${ }^{57} \mathrm{Fe} /{ }^{62} \mathrm{Ni} \times(3.63 / 2.12)$. This is about 20 -fold higher than the $\mathrm{Fe} / \mathrm{Ni}$ ratios observed in silicates in chondrules $\left(\sim 3 \times 10^{4}\right.$, Tachibana et al., 2006). This high ratio, combined with the old ages and relatively long measurement times of ${ }^{60} \mathrm{Ni}$ and ${ }^{62} \mathrm{Ni}$ isotopes, produced a good precision for the reported angrite results ${ }^{60} \mathrm{Fe} /{ }^{56} \mathrm{Fe}=[6 \pm 9(2 \sigma)] \times 10^{-9}$. The combined angrite data, 

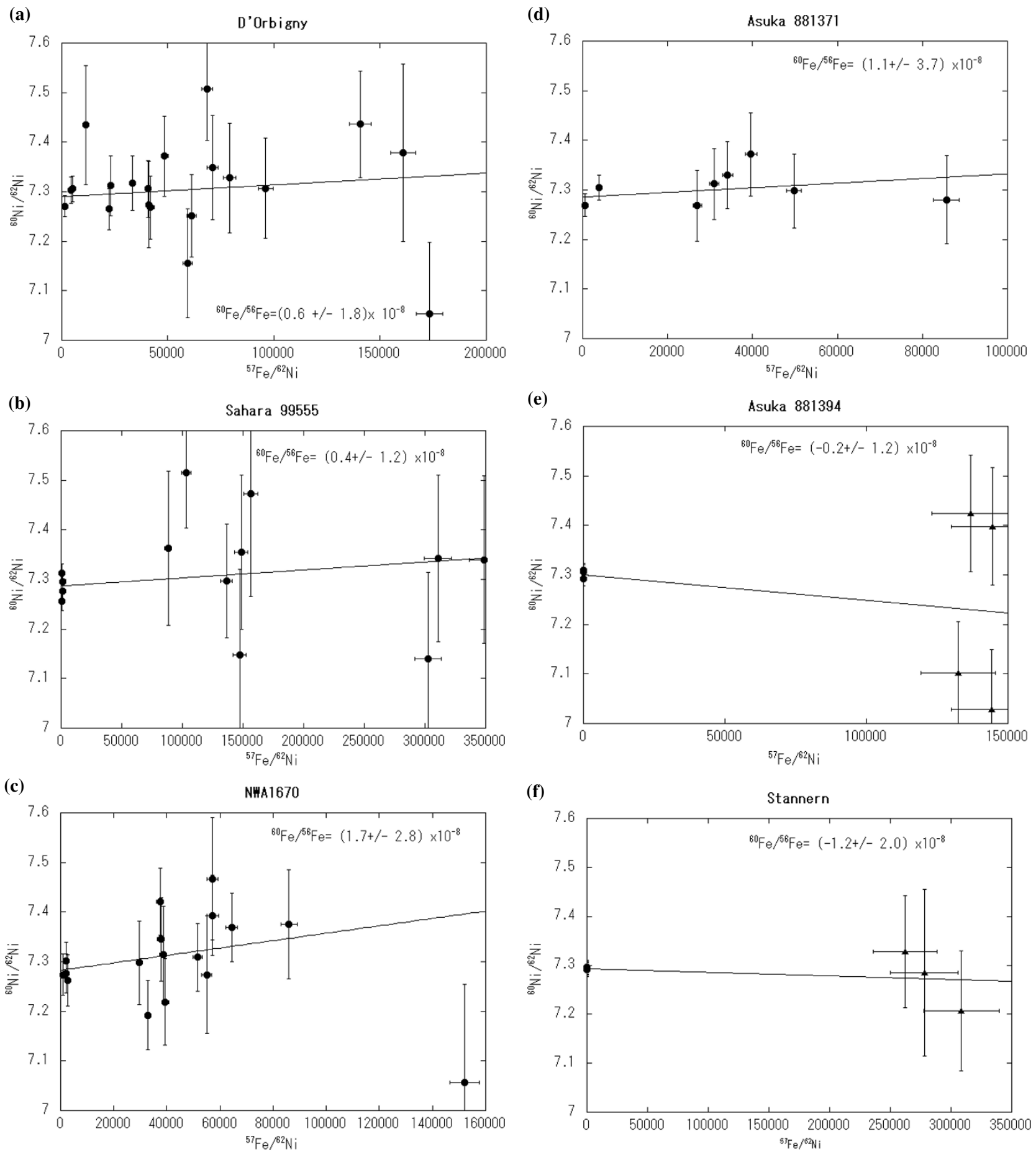

Fig. 2. ${ }^{60} \mathrm{Fe}-{ }^{60} \mathrm{Ni}$ isochron diagrams for (a) D’Orbigny, (b) Sahara 99555, (c) Northwest Africa 1670, (d) Asuka 881371, (e) Asuka 881394 and (f) Stannern. Error bars are $1 \sigma$. The inferred initial ${ }^{60} \mathrm{Fe} /{ }^{56} \mathrm{Fe}$ ratio with $2 \sigma$ error is given in each panel. Data points for olivine are shown by circles and those for pyroxene are shown by triangles.

using the age difference of approximately $5 \mathrm{Ma}$ between angrites and CAIs give an inferred initial ${ }^{60} \mathrm{Fe} /{ }^{56} \mathrm{Fe}$ ratio at the beginning of the solar system of $[6 \pm 9(2 \sigma)] \times 10^{-8}$.

The eucrites also do not show significant $\mathrm{Ni}$ isotope anomalies. The ${ }^{57} \mathrm{Fe} /{ }^{62} \mathrm{Ni}$ ratios are $1 \times 10^{5} \sim 3 \times 10^{5}$, which are not as high as that reported for a bulk sample of Juvinas (Shukolyukov and Lugmair, 1993b). The inferred initial ${ }^{60} \mathrm{Fe} /{ }^{56} \mathrm{Fe}$ ratios from Asuka 881394 and Stannern are similar. If we consider that Stannern is as old as Asuka 881394, as suggested by the Hf-W data, then both eucrites give an upper limit to the inferred ${ }^{60} \mathrm{Fe} /{ }^{56} \mathrm{Fe}$ initial ratio of approximately $6 \times 10^{-8}$ at the beginning of the solar system, which is consistent with that obtained from angrites. However, if the Fe-Ni system of Stannern is reset at $4.1 \mathrm{Ga}$, as suggested by the $\mathrm{Pb}-\mathrm{Pb}$ dating, then this eucrite does not provide significant constraints.

The present data from eucrites are consistent with the previously reported ${ }^{60} \mathrm{Ni}$ excesses for eucrites (Shukolyukov and Lugmair, 1993a, b). The Chervony Kut eucrite studied by Shukolyukov and Lugmair (1993a) 
Table 1. Initial ${ }^{60} \mathrm{Fe} /{ }^{56} \mathrm{Fe}$ ratios, ages from $\mathrm{CAI}$ and solar system initial ${ }^{60} \mathrm{Fe} /{ }^{56} \mathrm{Fe}$ ratios.

\begin{tabular}{llcc}
\hline & \multicolumn{1}{c}{${ }^{60} \mathrm{Fe} /{ }^{56} \mathrm{Fe}$} & Age from CAI & Solar system initial ${ }^{60} \mathrm{Fe} /{ }^{56} \mathrm{Fe}$ \\
\hline Angrites & $(0.6 \pm 1.8) \times 10^{-8}$ & $\sim 5 \mathrm{Ma}$ & \\
D'Orbigny & $(0.4 \pm 1.2) \times 10^{-8}$ & $\sim 5 \mathrm{Ma}$ & $(0.6 \pm 1.8) \times 10^{-7}$ \\
Sahara 99555 & $(1.7 \pm 2.8) \times 10^{-8}$ & $\sim 5 \mathrm{Ma}$ & $(0.4 \pm 1.2) \times 10^{-7}$ \\
NWA 1670 & $(1.1 \pm 3.7) \times 10^{-8}$ & $\sim 5 \mathrm{Ma}$ & $(1.7 \pm 2.8) \times 10^{-7}$ \\
Asuka 881371 & $(0.6 \pm 0.9) \times 10^{-8}$ & $\sim 5 \mathrm{Ma}$ & $(1.1 \pm 3.7) \times 10^{-7}$ \\
Four Angrites & & & \\
Eucrites & $(-1.2 \pm 2.0) \times 10^{-8}$ & $\sim 4 \mathrm{Ma}$ & $(-0.8 \pm 1.2) \times 10^{-7}$ \\
Asuka 881394 & $(-0.2 \pm 1.2) \times 10^{-8}$ & $\sim 4 \mathrm{Ma}$ & $(-0.1 \pm 0.8) \times 10^{-7}$ \\
Stannern & &
\end{tabular}

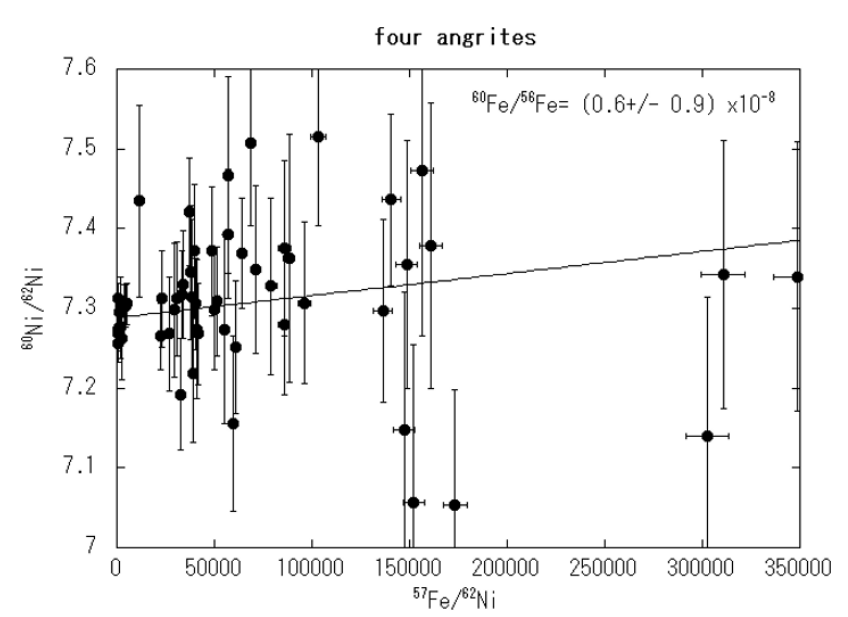

Fig. 3. ${ }^{60} \mathrm{Fe}-{ }^{60} \mathrm{Ni}$ isochron diagram for combined angrites.

and Asuka 881394 are about the same age. If an isochron is drawn through the pyroxene data for Chervony Kut and the origin of the isochron diagram, the inferred initial ${ }^{60} \mathrm{Fe} /{ }^{56} \mathrm{Fe}$ ratio is approximately $2 \times 10^{-9}$, which is consistent with the value of ${ }^{60} \mathrm{Fe} /{ }^{56} \mathrm{Fe}=(-1.2 \pm 2.0) \times 10^{-8}$ obtained from Asuka 881394 in this study. Note that bulk samples of Chervony Kut give a larger initial ${ }^{60} \mathrm{Fe} /{ }^{56} \mathrm{Fe}$ ratio of approximately $3.9 \times 10^{-9}$ (Shukolyukov and Lugmair, 1993a), which is the result of the internal mineral isochron being reset after the establishment of the bulk-sample isochron.

\section{Discussion}

Figure 4 is an age versus initial ${ }^{60} \mathrm{Fe} /{ }^{56} \mathrm{Fe}$ ratio diagram that includes most of the data published to date. The diagonal line represents the decay of ${ }^{60} \mathrm{Fe}$ with a half-life of approximately $1.5 \mathrm{Ma}$ and an initial ${ }^{60} \mathrm{Fe} /{ }^{56} \mathrm{Fe}$ ratio of $10^{-6}$ at the beginning of the solar system. The arrows directed downwards indicate that the data are upper limits for the initial ratios; those directed towards the right indicate that the ages could be younger. The range of the ${ }^{60} \mathrm{Fe} /{ }^{56} \mathrm{Fe}$ ratio expected for supernova ejecta $\left(3.2 \times 10^{-7}\right.$ to $\left.1.3 \times 10^{-5}\right)$ at the time of solar system formation (Wasserburg et al., 1998) and the ${ }^{60} \mathrm{Fe} /{ }^{56} \mathrm{Fe}$ ratio in the interstellar medium (Wasserburg et al., 1996) are also shown on the y-axis of Fig. 4. The initial ${ }^{60} \mathrm{Fe} /{ }^{56} \mathrm{Fe}$ ratio at the start of the solar system obtained in this study is consistent with previously reported

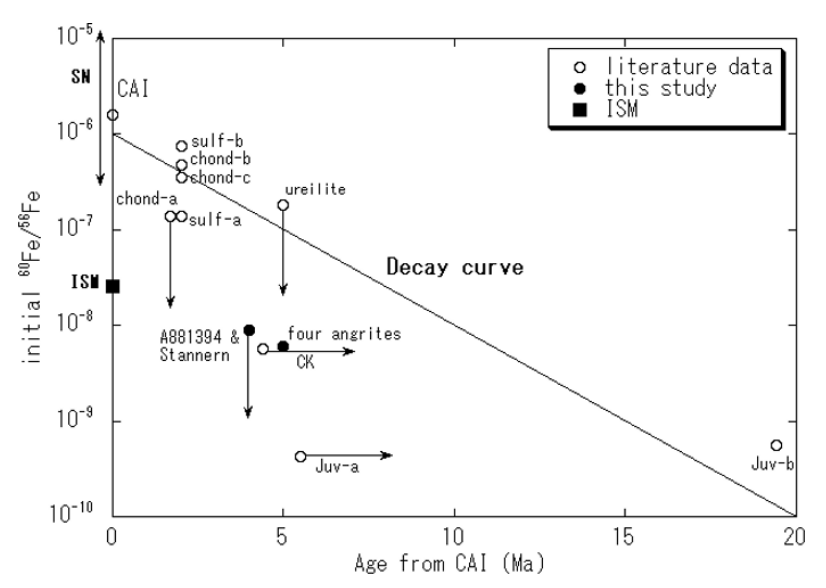

Fig. 4. Age versus initial ${ }^{60} \mathrm{Fe} /{ }^{56} \mathrm{Fe}$ ratio diagram. Data sources are given below. Errors are omitted for the sake of clearness. The diagonal line represents the decay of ${ }^{60} \mathrm{Fe}$ with a half-life of approximately $1.5 \mathrm{Ma}$. The arrows directed downwards indicate the upper limits of the initial ratios; those directed towards the right indicate that the ages could be younger. Also shown is the range of the ${ }^{60} \mathrm{Fe} /{ }^{56} \mathrm{Fe}$ ratio expected for supernova ejecta $\left(3.2 \times 10^{-7}\right.$ to $\left.1.3 \times 10^{-5}\right)$ at the time of solar system formation (Wasserburg et al., 1998) and the ${ }^{60} \mathrm{Fe} /{ }^{56} \mathrm{Fe}$ ratio in the interstellar medium (Wasserburg et al., 1996). CK (Shukolyukov and Lugmair, 1993a), Juv-a (Shukolyukov and Lugmair, 1993b), Juv-b (Quitte et al., 2005), sulf-a (Tachibana and Huss, 2003), sulf-b (Mostefaoui et al., 2004b, 2005), ureilite (Kita et al., 1998), chond-a (Kita et al., 2000), chond-b (Choi et al., 1999), chond-c (Tachibana et al., 2006). A881394, Stannern and angrites are from this study. Ages of sulfide-a, sulfide-b, chondrule-b and chondrule-c are assumed to be 2 Ma after CAI.

values from some eucrites but is significantly smaller than the previously reported initial ratios from some chondrites.

An apparently large initial ratio at the beginning of the solar system obtained from Juvinas eucrite (Juv-b in Fig. 4) is due to the choice of the young age (19.4 Ma after CAI) based on the Hf-W system (Quitte et al., 2005). The Hf-W system of eucrites is complicated as it shows partial reset of the mineral isochrons (Kleine et al., 2005). Yin et al. (2002) have measured Hf-W in Juvinas (whole rock) and concluded that the Juvinas and eucrites as a group post-date the beginning of the solar system by only $\sim 3 \mathrm{Ma}$. The ages of eucrites based on whole rock ${ }^{53} \mathrm{Mn}-{ }^{53} \mathrm{Cr}$ age (Lugmair and Shukolyukov, 1998) and model ${ }^{26} \mathrm{Al}-{ }^{26} \mathrm{Mg}$ ages (Bizzarro et al., 2005) are also very old. Furthermore, the relationship among Fe-Ni, Hf-W and $\mathrm{Mn}-\mathrm{Cr}$ ages is not well known. Therefore, it is not clear if the Juvinas datum should 
be plotted at 19.4 Ma after CAI. Shukolyukov and Lugmair (1993b) obtained an initial ${ }^{60} \mathrm{Fe} /{ }^{56} \mathrm{Fe}$ ratio for Juvinas that is similar to that reported by Quitte et al. (2005). In Fig. 4, this datum (Juv-a) is plotted at an age ( $\sim 6 \mathrm{Ma}$ after CAI) estimated from the Mn-Cr internal isochron (Lugmair and Shukolyukov, 1998). This choice of age is somewhat arbitrary but it cannot be approximately $3 \mathrm{Ma}$ after CAI because another eucrite, Chervony Kut (shown as CK in Fig. 4), showed a significantly larger ${ }^{60} \mathrm{Fe} /{ }^{56} \mathrm{Fe}$ ratio than Juvinas. If the age of Chervony Kut is set at approximately 3 Ma after CAI and if this is used as the upper limit age, then based on the difference in ${ }^{60} \mathrm{Fe} /{ }^{56} \mathrm{Fe}$ ratios between two eucrites the age of Juvinas should be younger than approximately 6 Ma from CAI. The datum for Chervony Kut is plotted at approximately $4 \mathrm{Ma}$ from CAI based on the Mn-Cr internal isochron (Lugmair and Shukolyukov, 1998). This choice of age is also somewhat arbitrary but is consistent with the expectation (see below) that the Fe-Ni system should close at a slightly lower temperature than the $\mathrm{Mn}-\mathrm{Cr}$ system that shows a whole rock age of approximately $3 \mathrm{Ma}$ after CAI (Lugmair and Shukolyukov, 1998). The best estimate of the initial ${ }^{60} \mathrm{Fe} /{ }^{56} \mathrm{Fe}$ ratio at the start of the solar system based on three (Chervony Kut, Juvinas and Caldera) eucrite data sets (Shukolyukov and Lugmair, 1996) is $6 \times 10^{-8}$, which agrees quite well with the results of this study.

With regard to chondritic materials, the present results are consistent with the upper limit reported by Kita et al. $\left(2000 ;<3.4 \times 10^{-7}\right)$ but are not consistent with large initial ratios obtained from sulfides (Tachibana and Huss, 2003; Mostefaoui et al., 2004a, b, 2005) and chondrules (Tachibana et al., 2006) if one assumes that ${ }^{60} \mathrm{Fe}$ was homogeneously distributed in the solar system.

Here we examine the possible reasons of apparent inconsistency between chondrites and achondrites in Fig. 4. One possibility is that the measurement technique is rather new and not well established; for example, even the same samples (metals in various meteorites) could yield significantly different results (Cook et al., 2005; Moynier et al., 2005). (Since precise chronological information is not available for these samples, their data are not plotted in Fig. 4). Further investigation of the various samples studied to date (including the ones from the present study) is needed to test the reproducibility of the results.

Another possible reason for inconsistent initial ${ }^{60} \mathrm{Fe} /{ }^{56} \mathrm{Fe}$ ratios is resetting of $\mathrm{Fe} / \mathrm{Ni}$ ratios in minerals after the presumed formation age. For example, sulfide minerals tend to be easily disturbed by mild heating (Tachibana and Huss, 2003; Kita et al., 2005). Troilite in Semarkona shows a high initial ${ }^{60} \mathrm{Fe} /{ }^{56} \mathrm{Fe}$ ratio $(9.2 \pm 2.4) \times 10^{-7}$ (Mostefaoui et al., 2004a, b, 2005) which, in fact, is higher than that obtained from magnetite in the same meteorite. The formation of the magnetite at $4 \sim 5 \mathrm{Ma}$ after the troilite was suggested by Mostefaoui et al. (2004a, 2005). However, the ratio for the sulfide in Semarkona is significantly higher than those for Bishunpur $(1.08 \pm 0.23) \times 10^{-7}$ and Krymka $(1.73 \pm 0.53) \times 10^{-7}$ (Tachibana and Huss, 2003). Such a large difference in $\mathrm{Fe}$ initial ratios cannot be easily attributed to differences in formation ages among the primitive chondrites. An alternative explanation may be changes in $\mathrm{Fe} / \mathrm{Ni}$ ratios in troilite during mild reheating, which is in accordance with Mostefaoui et al. (2005) who suggested that $\mathrm{Fe} / \mathrm{Ni}$ ratios can be expected to increase by mild heating. Hence, if the Fe-Ni system in Bishunpur and Krymka has been disturbed, the initial ratios are considered to be lower limits.

A similar problem exists in the case of eucrites. Chervony Kut (CK) and Juvinas (Juv-a) data in Fig. 4 are inconsistent with each other unless Juvinas is approximately 5 Ma younger than Chervony Kut. The age difference is only approximately $1 \mathrm{Ma}$ according to the $\mathrm{Mn}-\mathrm{Cr}$ internal isochrons, suggesting that $\mathrm{Fe}-\mathrm{Ni}$ system was disturbed in a late metamorphic event that did not disturb the $\mathrm{Mn}-\mathrm{Cr}$ system. It is important to note that the Fe-Ni system in pyroxene, which is expected to have high closure temperatures (Kita et al., 2005), has been disturbed in these eucrites. Therefore, it is possible that the Fe-Ni system in the eucrite samples in this study has also been disturbed. We note, however, that Asuka 881394 is the only eucrite that shows an isochron age in the Al-Mg system, which means that Asuka 881394 is the least altered eucrite among the whole collection of eucrites; consequently, there is a definite possibility that the Fe-Ni system has not been disturbed since its formation. Future studies on bulk samples of Asuka 881394 will provide answers to this issue.

In the same context, it is important to determine if the $\mathrm{Fe}$ $\mathrm{Ni}$ system of the angrites has been disturbed. The $\mathrm{Mn}-\mathrm{Cr}$ system of quenched angrites shows good internal isochrons (Sugiura et al., 2005), while that of the Al-Mg system also shows a reasonably good internal isochron (SpivakBirndorf et al., 2005a, b). These data serve as good supporting evidence for an undisturbed $\mathrm{Fe}-\mathrm{Ni}$ system in quenched angrites. More rigorous arguments can be made based on diffusion rates in olivine and anorthite. The diffusion rates of $\mathrm{Ni}, \mathrm{Fe}-\mathrm{Mg}$ and $\mathrm{Mn}$ in olivine were reported by Petry et al. (2004), while the diffusion of $\mathrm{Cr}$ in olivine was studied by Ito and Ganguly (2006), and that of $\mathrm{Mg}$ in anorthite was studied by LaTourrette and Wasserburg (1998). According to these studies, $\mathrm{Ni}$ diffusion rates in olivine are somewhat faster than those of $\mathrm{Cr}$. This is consistent with the robust $\mathrm{Mn}-\mathrm{Cr}$ system compared with the Fe-Ni system in eucrites. More importantly, Ni diffusion in olivine is slower than $\mathrm{Mg}$ diffusion in anorthite, which indicates that the Fe-Ni system in olivine is more robust than the $\mathrm{Al}-\mathrm{Mg}$ system in anorthite. Therefore, preservation of the Al-Mg internal isochron in angrites suggests that the $\mathrm{Fe}-\mathrm{Ni}$ system in olivine has not been disturbed and that the small initial ${ }^{60} \mathrm{Fe} /{ }^{56} \mathrm{Fe}$ ratios for the quenched angrites were established at approximately 5 Ma after the CAIs. Future high-precision studies of bulk angrite samples will give significantly stricter constraints on the initial ${ }^{60} \mathrm{Fe} /{ }^{56} \mathrm{Fe}$ ratio at the start of the solar system. The absence of ${ }^{60} \mathrm{Fe}$ we report here and which was reported in Sugiura and Yin (2005) is now corroborated by a recent finding in one of the four quenched angrites, Sahara 99555, by high-precision MC-ICP-MS measurement (Bizzarro et al., 2006; reported at the 34th LPSC Meeting).

The same reasoning can be applied to chondrules in primitive chondrites. Although $\mathrm{Al}-\mathrm{Mg}$ systematics was not determined on the same chondrules for which positive ${ }^{60} \mathrm{Fe} /{ }^{56} \mathrm{Fe}$ ratios were obtained (Tachibana et al., 2006), internal $\mathrm{Al}-\mathrm{Mg}$ isochrons have been obtained in many chon- 
drules in primitive chondrites (Kita et al., 2000). Hence we expect that the Fe-Ni system has not been disturbed in these chondrules. Nevertheless, the initial ${ }^{60} \mathrm{Fe} /{ }^{56} \mathrm{Fe}$ ratio at the start of the solar system obtained from chondrules is significantly different from that obtained from quenched angrites.

At present, we have no reason to discard any particular data in Fig. 4. If all the data are taken at face value we have to conclude that the solar system was heterogeneous with respect to ${ }^{60} \mathrm{Fe}$. There are several lines of evidence that suggest significant heterogeneity of the solar nebula (Gounelle and Russell, 2005). Observations of ${ }^{53} \mathrm{Cr}$ isotope anomalies in various meteorites suggest that ${ }^{53} \mathrm{Mn}$ was heterogeneously distributed in the solar system (Shukolyukov and Lugmair, 2004). It is also suggested that ${ }^{53} \mathrm{Mn}$ abundances in CAIs were much larger than those in other chondritic materials (Papanastassiou et al., 2005). The absence of ${ }^{26} \mathrm{Al}$ in FUN inclusions suggests that ${ }^{26} \mathrm{Al}$ may also be distributed heterogeneously, although this heterogeneity could be temporal rather than spatial. Oxygen and nitrogen isotope anomalies in various meteorites (Clayton et al., 1976; Franchi et al., 1993) also suggest that the solar nebula was heterogeneous either temporarily or spatially. A theoretical study (Boss, 2004) suggested that heterogeneity in the nebula could survive for approximately $10^{3}$ years. Thus, although it is premature to claim that the solar nebula was heterogeneous based on the ${ }^{60} \mathrm{Fe}$ data, heterogeneity is a possible explanation of Fig. 4.

The importance of ${ }^{60} \mathrm{Fe}$ as a heat source was discussed by Shukolyukov and Lugmair (1993a). In their study, initial ${ }^{60} \mathrm{Fe} /{ }^{56} \mathrm{Fe}$ ratios ranging from $1 \times 10^{-6}$ to $2 \times 10^{-6}$ were assumed at the time of planetesimal accretion. The temperature increase due to decay of ${ }^{60} \mathrm{Fe}$ was calculated to range from $\sim 850 \mathrm{~K}$ to $\sim 1700 \mathrm{~K}$, which is proportional to the ${ }^{60} \mathrm{Fe} /{ }^{56} \mathrm{Fe}$ ratio. The present results suggest that if parent-bodies of achondrites accreted 1.5 Ma after CAI, the ${ }^{60} \mathrm{Fe} /{ }^{56} \mathrm{Fe}$ ratio was approximately $3 \times 10^{-8}$. Therefore, the increase in the temperature due to ${ }^{60} \mathrm{Fe}$ decay was only approximately $25 \mathrm{~K}$.

\section{Conclusions}

${ }^{60} \mathrm{Fe}-{ }^{60} \mathrm{Ni}$ systematics in angrites and eucrites were investigated by secondary ion mass spectrometry. The inferred initial ${ }^{60} \mathrm{Fe} /{ }^{56} \mathrm{Fe}$ ratio for quenched angrites was $[6 \pm 9(2 \sigma)] \times 10^{-9}$. Similar upper limit values were also obtained from eucrites. Using the age difference of approximately 5 Ma between the quenched angrites and CAIs, the initial ${ }^{60} \mathrm{Fe} /{ }^{56} \mathrm{Fe}$ ratio at the start of the solar system was calculated to be approximately $[6 \pm 9(2 \sigma)] \times 10^{-8}$. This initial ratio is significantly smaller than some of the literature values obtained from chondritic materials. According to diffusion rates of $\mathrm{Ni}$ in olivine and $\mathrm{Mg}$ in anorthite, the $\mathrm{Fe}-\mathrm{Ni}$ system in olivine should be more robust than $\mathrm{Al}-\mathrm{Mg}$ system in anorthite. Therefore, the Fe-Ni system of olivine in achondrites that preserved an Al-Mg internal isochron was unlikely to have been disturbed by late metamorphism. Heterogeneous distribution of ${ }^{60} \mathrm{Fe}$ in the solar nebula is a possible solution for the discrepancy of initial ${ }^{60} \mathrm{Fe} /{ }^{56} \mathrm{Fe}$ ratios among various meteorites.

Acknowledgments. The authors would like to thank the Na- tional Institute of Polar Research for providing valuable samples. This work was supported by grants-in-aid of science research (14340169) from the Japanese Society for Promotion of Science. Drs. H. Hiyagon, T. Ushikubo and K. Yanai are thanked for many helpful discussions. QZY acknowledges the NASA Cosmochemistry and Origins of Solar System Programs for support.

\section{References}

Amelin, Y., A. N. Krot, I. D. Hutcheon, and A. A. Ulyanov, Lead isotopic ages of chondrules and calcium-aluminum-rich inclusions, Science, 297, 1678-1683, 2002.

Baker, J., M. Bizzaro, N. Wittig, J. Connelly, and H. Haack, Early planetesimal melting from an age of $4.5662 \mathrm{Gyr}$ for differentiated meteorites, Nature, 435, 1127-1131, 2005.

Birck, J. L. and G. W. Lugmair, Nickel and chromium isotopes in Allende inclusions, Earth Planet. Sci. Lett., 90, 131-143, 1988.

Bizzarro, M., J. A. Baker, H. Haack, and K. L. Lundgaard, Rapid timescales for accretion and melting of differentiated planetesimals inferred from ${ }^{26} \mathrm{Al}-{ }^{26} \mathrm{Mg}$ chronometry, Astrophys. J., 632, L41-L44, 2005.

Bizzarro, M., D. Ulfbeck, and K. Thrane, Nickel isotopes in meteorites: Evidence for live ${ }^{60} \mathrm{Fe}$ and distinct ${ }^{62} \mathrm{Ni}$ isotope reservoirs in the early Solar System, Lunar Planet. Sci., 37, 2020.pdf, 2006.

Boss, A., Evolution of the solar nebula. VI. Mixing and transport of isotopic heterogeneity, Astrophys. J., 616, 1265-1277, 2004.

Choi, B.-G., G. R. Huss, and G. J. Wasserburg, Search for a correlation between ${ }^{60} \mathrm{Fe}$ and ${ }^{26} \mathrm{Al}$ in chondrites, Lunar Planet. Sci., 30, 1999.

Clayton, R. N., N. Onuma, and T. K. Mayeda, Classification of meteorites based on oxygen isotopes, Earth Planet. Sci. Lett., 30, 10-18, 1976.

Cook, D. L., M. Wadhwa, R. N. Clayton, P. E. Janney, N. Dauphas, and A. M. Davis, Nickel isotope compositions of meteoritic metal: Implications for the initial ${ }^{60} \mathrm{Fe} /{ }^{56} \mathrm{Fe}$ ratio in the early solar system, Meteoritics Planet. Sci., 40, 5136.pdf, 2005.

Franchi, I. A., I. P. Wright, and C. T. Pillinger, Constraints on the formation conditions of iron-meteorites based on concentrations and isotopic compositions of nitrogen, Geochim. Cosmochim. Acta, 57, 3105-3121, 1993.

Glavin, D. P., A. Kubny, E. Jagoutz, and G. W. Lugmair, Mn-Cr isotope systematics of the D'Orbigny angrite, Meteoritics Planet. Sci., 39, 693$700,2004$.

Goswami, J. N., K. K. Marhas, M. Chaussidon, M. Gounelle, and B. S. Meyer, Origin of short-lived radionuclides in the early solar system, in Chondrites and the Protoplanetary Disk, edited by A. N. Krot, E. R. D. Scott, and B. Reipurth, ASP Conference Series, Vol. 341, pp. 485-514, 2005.

Gounelle, M. and S. S. Russell, Spatial heterogeneity of short-lived isotopes in the solar accretion disk and early solar system chronology, in Chondrites and the Protoplanetary Disk, edited by A. N. Krot, E. R. D. Scott, and B. Reipurth, ASP Conference Series, Vol. 341, pp. 588-601, 2005.

Ito, M. and J. Ganguly, Diffusion kinetics of $\mathrm{Cr}$ in olivine and ${ }^{53} \mathrm{Mn}-{ }^{53} \mathrm{Cr}$ thermo-chronology of early solar system objects, Geochim. Cosmochim. Acta, 70, 799-809, 2006.

Kita, N. T., S. Togashi, Y. Morishita, S. Terashima, and H. Yurimoto, Search for ${ }^{60} \mathrm{Ni}$ excesses in MET-78008 ureilite: an ion microprobe study, Antarctic Meteorite Res., 11, 103-121, 1998.

Kita, N. T., H. Nagahara, S. Togashi, and Y. Morishita, A short duration of chondrule formation in the solar nebula: Evidence from ${ }^{26} \mathrm{Al}$ in Semarkona ferromagnesian chondrules, Geochim. Cosmochim. Acta, 64, 3913-3922, 2000.

Kita, N. T., G. R. Huss, S. Tachibana, Y. Amelin, L. E. Nyquist, and I. D. Hutchson, Constraints on the origin of chondrules and CAIs from short-lived and long-lived radionuclides, in Chondrites and the Protoplanetary Disk, edited by A. N. Krot, E. R. D. Scott, and B. Reipurth, ASP Conference Series, Vol. 341, pp. 558-587, 2005.

Kleine, T., K. Mezger, H. Palme, E. Scherer, and C. Munker, The W isotope composition of eucrite metal: constraints on the timing and cause of the thermal metamorphism of basaltic eucrites, Earth Planet. Sci. Lett., 231, 41-52, 2005.

LaTourrette, T. and G. J. Wasserburg, Mg diffusion in anorthite: implications for the formation of early solar system planetesimals, Earth Planet. Sci. Lett., 158, 91-108, 1998.

Lehmann, H., Investigation of the matrix effect of $\mathrm{Mg}, \mathrm{Si}, \mathrm{Ca}, \mathrm{Sc}, \mathrm{Fe}, \mathrm{Y}$, $\mathrm{La}$ and $\mathrm{Lu}$ in pyroxene composition synthetic silicate glasses by ion microprobe, Geostandards Newsl., 27, 99-117, 2003. 
Lugmair, G. W. and A. Shukolyukov, Early solar system timescales according to ${ }^{53} \mathrm{Mn}-{ }^{53} \mathrm{Cr}$ systematics, Geochim. Cosmochim. Acta, 62, 28632886, 1998.

MacPherson, G. J., A. M. Davis, and E. K. Zinner, The distribution of aluminum-26 in the early Solar System-A reappraisal, Meteoritics, 30, 365-386, 1995.

Mikouchi, T., M. Miyamoto, G. McKay, and L. Le, Cooling rate estimates of quenched angrites: Approach by crystallization experiments and cooling calculations of olivine xenocrysts, Meteoritics Planet. Sci., 36, A134-135, 2001.

Mostefaoui, S., G. W. Lugmair, and P. Hoppe, In-situ evidence for live iron-60 in the early solar system: A potential heat source for planetary differentiation from a nearby supernova explosion, Lunar Planet. Sci., 35, 1271.pdf, 2004a.

Mostefaoui, S., G. W. Lugmair, P. Hoppe, and A. El Goresy, Evidence for live ${ }^{60} \mathrm{Fe}$ in meteorites, New Astron. Rev., 48, 155-159, 2004b.

Mostefaoui, S., G. W. Lugmair, and P. Hoppe, ${ }^{60} \mathrm{Fe}$ : A heat source for planetary differentiation from a nearby supernova explosion, Astrophys. $J ., 625,271-277,2005$.

Moynier, F., J. Blichert-Toft, P. Telouk, and F. Albarede, Excesses of ${ }^{60} \mathrm{Ni}$ in chondrites and iron meteorites, Lunar Planet. Sci., 36, 1593.pdf, 2005.

Nyquist, L. E., C. Y. Shih, H. Weismann, and T. Mikoichi, Fossil ${ }^{26} \mathrm{Al}$ and ${ }^{53} \mathrm{Mn}$ in D'Orbigny and Sahara 99555 and the time scale for angrite magmatism, Lunar Planet. Sci., 34, 1388.pdf, 2003a.

Nyquist, L. E., Y. Reese, H. Wiesmann, C.-Y. Shih, and H. Takeda, Fossil ${ }^{26} \mathrm{Al}$ and ${ }^{53} \mathrm{Mn}$ in the Asuka 881394 eucrite: evidence of the earliest crust on the asteroid 4 Vesta, Earth Planet. Sci. Lett., 214, 11-25, 2003b.

Papanastassiou, D. A., G. J. Wasserburg, and O. Bogdanovski, The ${ }^{53} \mathrm{Mn}-$ ${ }^{53}$ Cr system in CAIs: An update, Lunar Planet. Sci., 36, 2198.pdf, 2005.

Petry, C., S. Chakraborty, and H. Palme, Experimental determination of $\mathrm{Ni}$ diffusion coefficients in olivine and their dependence on temperature, composition, oxygen fugacity, and crystallographic orientation, Geochim. Cosmochim. Acta, 68, 4179-4188, 2004.

Quitte, G., C. Latkoczy, A. N. Halliday, M. Schonbachler, and D. Gunther, Iron-60 in the eucrite parent body and the initial ${ }^{60} \mathrm{Fe} /{ }^{56} \mathrm{Fe}$ of the solar system, Lunar Planet. Sci., 36, 1827.pdf, 2005.

Reed, S. J. B., E. R. D. Scott, and J. V. P. Long, Ion microprobe analysis of olivine in pallasite meteorites for nickel, Earth Planet. Sci. Lett., 43, 5-12, 1979.

Shukolyukov, A. and G. Lugmair, Live iron-60 in the early solar system, Science, 259, 1138-1142, 1993a.

Shukolyukov, A. and G. Lugmair, ${ }^{60} \mathrm{Fe}$ in eucrites, Earth Planet. Sci. Lett., 119, 159-166, 1993b.

Shukolyukov, A. and G. Lugmair, Iron-60/nickel-60 isotope system in the eucrite Caldera, Meteoritics Planet. Sci., 31, A129, 1996.
Shukolyukov, A. and G. W. Lugmair, Manganese-chromium isotope systematics of enstatite meteorites, Geochim. Cosmochim. Acta, 68, 28752888, 2004.

Spivak-Birndorf, L., M. Wadhwa, and P. E. Janney, ${ }^{26} \mathrm{Al}-{ }^{26} \mathrm{Mg}$ chronology of the D'Orbigny and Sahara 99555 angrites, Meteoritic Planet. Sci., 40, 5097.pdf, 2005a.

Spivak-Birndorf, L., M. Wadhwa, P. E. Janney, and C. N. Foley, Al-Mg isotopic systematics in the angrite Sahara 99555 and the primitive achondrite Brachina, Lunar Planet. Sci., 36, 2201.pdf, 2005b.

Steele, I. M., R. L. Hervig, I. D. Hutcheon, and J. V. Smith, Ion microprobe techniques and analyses of olivine and low-Ca pyroxene, Am. Mineral, 66, 526-546, 1981.

Sugiura, N. and Q. -Z. Yin, ${ }^{60} \mathrm{Fe}-{ }^{60} \mathrm{Ni}$ systematics of some achondrites, Meteoritics Planet. Sci., 40, 5061.pdf, 2005.

Sugiura, N., A. Miyazaki, and K. Yanai, Widespread magmatic activities on the angrite parent body at $4562 \mathrm{Ma}$ ago, Earth Planets Space, 57, e13-e16, 2005.

Tachibana, S. and G. R. Huss, The initial abundance of ${ }^{60} \mathrm{Fe}$ in the solar system, Astrophys. J., 588, L41-L44, 2003.

Tachibana, S., G. R. Huss, N. T. Kita, H. Shimoda, and Y. Morishita, ${ }^{60} \mathrm{Fe}$ in chondrites: Debris from a nearby supernova in the early Solar System? Astrophys. J., 639, L87-90, 2006.

Tera, F., R. W. Carlson, and N. Z. Boctor, Radiometric ages of basaltic achondrites and their relation to the early history of the solar system, Geochim. Cosmochim. Acta, 61, 1713-1731, 1997.

Wadhwa, M., Y. Amelin, O. Bogdanovski, A. Shukolyukov, G. W. Lugmair, and P. Janney, High precision relative and absolute ages for Asuka 881394, a unique and ancient basalt, Lunar Planet. Sci., 36, 2126.pdf, 2005.

Wasserburg, G. J., M. Busso, and R. Gallino, Abundances of actinides and short-lived nonactinides in the interstellar medium: diverse supernova sources for the r-processes, Astrophys. J., 466, L109-L113, 1996.

Wasserburg, G. J., R. Gallino, and M. Busso, A test of the supernova trigger hypothesis with ${ }^{60} \mathrm{Fe}$ and ${ }^{26} \mathrm{Al}$, Astrophys. J., 500, L189-L193, 1998.

Yin, Q.-Z., S. B. Jacobsen, K. Yamashita, J. Blichert-Toft, P. Telouk, and F. Albarede, A short timescale for terrestrial planet formation from Hf-W chronometry of meteorites, Nature, 418, 949-952, 2002.

Zartman, R. E., E. Jagoutz, and S. A. Bowring, $\mathrm{Pb}-\mathrm{Pb}$ dating of the D'Orbigny and Asuka 881371 angrites and a second absolute time calibration of the Mn-Cr chronometer, Lunar Planet. Sci., 37, 1580.pdf, 2006.

N. Sugiura (e-mail: sugiura@eps.s.u-tokyo.ac.jp), A. Miyazaki, and Q.-Z. Yin 